\title{
Children, Outdoor Play, and Loose Parts
}

\author{
Caileigh Flannigan and Beverlie Dietze
}

Caileigh Flannigan, MACYS, is a clinical therapist with Chimo Youth and Family Services in Ontario. She specializes in play, art, and nature therapies to support children's mental health. Her research interests include outdoor play and early childhood development. Caileigh spends her free time promoting unstructured outdoor play opportunities in city spaces. Email: caileigh.flannigan@gmail. com

Beverlie Dietze, $\mathbf{P h D}$, is the director of learning and teaching at Okanagan College, Kelowna, BC. Her research interests include outdoor play environments for children and early learning and child care professional staff development models. She was educated at Sheridan College, the University of New Brunswick, St. Francis Xavier University, and the University of Toronto. Email: bdietze@ okanagan.bc.ca

In an effort to understand how loose parts in early learning environments benefit children's play and development, through observations of preschool children in a rural outdoor natural environment, this study examined behaviours that children exhibited as they used loose parts. Children exhibited a range of positive social behaviours, complex verbal and nonverbal behaviours, and various types of risk taking in their play. The findings suggest that children do not explicitly exhibit stereotypical gender or age-exclusion behaviours while using the loose parts. The results would suggest that increasing children's opportunities to use loose parts in an early years outdoor environment will support their various aspects of development in positive ways.

Key words: outdoor play; loose parts; early childhood development; unstructured play; natural environments; play development
Play, especially outdoor play, is a crucial component of early childhood. Play is innate and instinctual for children. Play influences children's learning and development. Chakravarthi (2009) defined play as an act that is "meaningful, intrinsically motivating, pleasurable, freely chosen, symbolic, actively engaging and opportunistic" and suggested that it be considered as "episodic, imaginative and creative and fluid and active" (p. 25). According to Chakravarthi, both Piaget and Vygotsky viewed children's play as encompassing "creativity, exploration, experimentation, adaptation, learning, communication and socialization" (p. 25).

Despite past and present knowledge of the importance of play to early childhood learning and development, there has been a national trend over the past decade of reducing outdoor play in school and community settings (Milteer \& Ginsburg, 2012). In many countries, including the United Kingdom (Waller, 2007), Denmark, and Norway, access to and opportunities for children to engage in long periods of outdoor play in the early years are being promoted and practiced (Ernst, 2014). As children's rates of obesity, diabetes, and depression increase, many communities in Canada are rethinking the importance of outdoor play to child development and wondering how to increase children's time and levels of activity outdoors (Tremblay et al., 2015). One strategy that is being promoted is for children to have exposure to outdoor play environments that have a variety of natural and synthetic loose parts. Loose parts refers to play objects and materials that are open ended and manipulable (Nicholson, 1971). Loose parts are moveable, nondictated materials that children can use in a variety of ways (Daly \& Beloglovsky, 2015; Maxwell, Mitchell, \& Evans, 2008).

When children have exposure to intriguing loose parts, they become curious. Children's curiosity is triggered when they see and experience new things and have unique experiences that may not be possible in the indoor environment. This sense of curiosity is how children become inspired to engage in new explorations and discoveries 
(Perry, 2004). The quality and depth of outdoor play experiences can be increased when loose parts are added to the outdoor environment (Änggård, 2011; Maxwell et al., 2008). Loose parts give children the freedom to develop their play experiences based on their ideas and goals, rather than the play being predetermined by the materials or surroundings (Änggård, 2011). This means that the materials do not dictate the type of play children engage in. Children create play episodes based on their past experiences, curiosity, creativity, and new ideas.

Loose parts and the fluctuating outdoor environment create affordances for children. Affordances are the possibilities that an environmental feature or object provides to an individual. The perception of such possibilities leads children to act on that feature or object (Gibson, 1977). Therefore, a feature within an outdoor environment may have multiple uses based on children's perceptions of what could be. For example, a rock could be perceived as something to throw or to climb over. A stick could be perceived as a sword or as a tool for digging. The way children perceive a loose part influences if and how they use it in their play. Since loose parts do not have a predetermined use or outcome, with experience, children can adapt them to be used in multiple ways. The theory of loose parts and affordances provides educators with insight into how loose parts in outdoor environments support children in being able to create rich and diverse play experiences.

Loose parts offer children opportunities for unstructured play that is not dominated by adults (Ridgers, Knowles, \& Sayers, 2012; Staempfli, 2009). Unstructured environments have limited guidelines and rules set by adults, allowing and encouraging children to create their own play activities. Outdoor play environments with loose parts that are changed regularly provide children with challenges and a sense of wonder, because the potential play experiences are constantly changing (Boldemann et al., 2006; Canning, 2010). Early learning teachers and programs that embrace the use of loose parts outdoors generally have more flexible schedules, while encouraging children to exercise their freedom to play and develop individual control and self-regulation skills (Stephenson, 2002). Loose parts promote varied play activities among preschool children (Zamani, 2012).

We contend that outdoor play environments with loose parts support children in having higher levels of engagement in their play than environments with more stationary equipment or materials with defined purposes. Loose parts in outdoor play environments have a positive influence on children's play behaviours and their development.

\section{The Study}

This study focused on examining the children's play themes, patterns, and behaviours that became evident with the use of familiar loose parts in a natural outdoor environment. The study was divided into two parts. Part one focused on observing how children used the preexisting loose parts that were familiar and available to them in their outdoor space daily. Part two involved observing children's play when unfamiliar loose parts were introduced in the outdoor environment. This paper focuses on part one of the study.

\section{Methodology}

This phase of the study involved gathering data on how the children played with familiar and frequently used loose parts (part one) in order to compare their play when new materials were provided. This study was guided by Bronfenbrenners's (1979) ecological theory, which proposes that there is a relationship between environmental and social factors and children's development (Dietze \& Kashin, 2012). These factors influence children through five environmental systems: microsystem, mesosystem, exosystem, macrosystem, and chronosystem (Bronfenbrenner, 1979), all of which can contribute to how children execute their play experiences (Dietze \& Kashin, 2012). Further, children's play is influenced by their family, educators, federal and provincial policies, culture and societal ideologies, and environmental conditions. 
Initial meetings were held at a childcare centre with the early childhood educators and the families of the children involved in the research. The purpose of the meetings was to discuss the project, examine families' and educators' views on loose parts and risk taking, and gather information on the availability of play opportunities within the community. The themes that evolved from these meetings suggested that all early childhood educators at the centre promoted the use of loose parts in the outdoors. However, some parents were unsure as to how such materials benefited their children. Structured metal playgrounds, rather than loose parts, were common within their community.

A total of 27 preschool children (11 females and 16 males) between the ages of 4 and 5 and four early childhood educators were involved in the research. Each part of the project consisted of three naturalistic observations (six total) using a digital video camera that was mounted on a tripod for stability. The video camera was moved around the play space to capture children's various play episodes. In an effort to answer the question regarding if and how the familiar loose parts influenced children's play themes and patterns and how they encouraged development, observations were conducted over three weeks on three different occasions. They were completed in an outdoor play green space located at the front of the childcare building. The space is fenced by trees and shrubbery and is approximately 100 by 50 metres in size. Digital recordings were made of the play interactions as they occurred from their beginning to their natural ending point. Field notes were taken during each observational day as a way of collecting information on weather conditions, verbal language, and notes about particular play episodes. Field notes were used to gather ongoing records of behaviours and play to give continuity to the video data.

\section{Loose part materials}

Children's play with the loose parts consisted of both natural and synthetic materials. Table 1 identifies the specific materials provided for each observation day.

Table 1. Schedule of Loose Parts

\begin{tabular}{cl}
\hline Day & \multicolumn{1}{c}{ Loose Parts } \\
\hline 1 & $\begin{array}{l}\text { Rope, garbage can, plastic pipes, angled plywood pieces, } \\
\text { buckets, buoys, tires, crates, dishes, clay trays, nets }\end{array}$ \\
2 & $\begin{array}{l}\text { Shovels, trays, tires, pieces of driftwood, rope, plastic tube, } \\
\text { large crate, rocks } \\
3\end{array}$ \\
Tire, buoys, pieces of wood, rope, crate, hoola hoop, fishing \\
net, buckets, pipes, tubes, dishes
\end{tabular}

\section{Data analysis}

The video data was transcribed after each daily observation as a way to provide a detailed narrative of the play and developmental behaviours. The narrative transcripts were analyzed to seek out themes related to verbal and nonverbal interactions, social behaviours, physical activity, risk taking, types and patterns of play, as well as age and gender behaviours. Coding of the data was conducted after the video footage had been analyzed and was put into categories or recurring themes. The patterns of behaviours observed during play that used loose parts were noted. 


\section{Findings}

\section{Play themes}

The most common theme identified was that of weapon/gun play. This may be due to children enjoying the freedom of outdoor spaces and the openness of the early childhood educators to movement and verbal expression, such as running, chasing, fleeing, climbing, and screaming, which are all common movements of weapon play (Rich, 2003). Observations noted that children used the sticks, pipe, or other long, skinny objects as weapons and wood pieces and cans as shields. Other common themes observed included family roles and dramatic play that included good versus bad roles. For example, children would take on the role of mother, father, and baby. The good versus bad roles included children playing out roles such as devils, intruders, and bad guys.

\section{Play patterns}

A common pattern observed was that the play episodes were goal oriented and involved shared activities. Most of the play episodes included children working toward achieving common goals, such as finding materials for their home, chasing the bad guy, or making food. Each child would have a role assigned and they would work together to execute the play episode.

The use of the affordances of the natural environment was also observed as a common pattern. The natural materials afforded by the environment were used frequently during play episodes for functional and dramatic play purposes. For example, children would jump and walk and squat over a pile of logs (functional use). Children also considered this same pile of logs to be a "fire" that they had to make bigger by piling on more logs and sticks. The functional uses were associated with the dramatic play as part of the fire. For example, the boys either wanted to get warm by squatting near the pretend fire or they would try to avoid getting burned by jumping over the fire (dramatic play). It seems that when loose parts are available to children, they not only perceive the functional use of the environment or materials, but also view such items as sticks, leaves, and trees as having imaginary qualities that children can incorporate into play episodes. It would appear that children did not view the natural materials as having to be used a certain way; therefore, their imaginations were enhanced by being able to ascribe whatever role they wished onto the materials.

\section{Social behaviours}

Positive social behaviours were apparent and consisted of turn taking, leadership, cooperation, decision making, assigning roles, assigning tasks, problem solving, curiosity, and the inclusion of others in discussions of tasks or themes. The most prevalent negative behaviours observed were tattling, bossiness, testing of social limits, and exclusion of others. The features of outdoor natural environments that include loose parts appeared to impose less structure on what the children played with and with whom they interacted. This encouraged children to engage in higher levels of social interaction and peer play, due in part to their openness, flexibility, and equity.

\section{Verbal and nonverbal behaviours}

Children engaged in a number of common verbal patterns: imitation, repetition, stating the theme, expressions of happiness or excitement, crying/whining, making noises that indicated a dramatic role, giving verbal demands or directions, making verbal requests for information or action, and using socially inclusive phrases of "we" or "ours," such as "we have to go get the bad guys," "this tree stump is ours and we must protect it," and "we are going to make smoothies with these pine needles." It was noted in most digital recordings that children were making loud yells and screams, separate from the verbal communication. This screaming could be attributed to their excitement over the materials, the accessibility of the open field, or simply being in nature. Common nonverbal behaviours 
were nodding, handing of materials back and forth to create and build, pointing, turning toward / away from, onlooking behaviours, raising objects or hands, examining materials, displays of distress, cautious behaviours, pushing/pulling, and placement of body on materials.

The outdoor environment provides a rich context that supports children in developing language and communication skills. A peaceful area surrounded by nature and free of background noise can motivate children to express themselves. Children can use their voice in a variety of ways, including pitches and volumes, without the usual constraints imposed in the indoor environments. The addition of loose parts in an outdoor environment provides further language development through the use of unfamiliar objects, new experiences, and the array of play possibilities.

\section{Risk-taking behaviours}

Many observations illustrated children's risk-taking behaviours. For example, children were observed climbing trees, swinging fast on a tree-rope, climbing on a pile of sticks, and walking across a tightrope. The behaviours revealed ways in which the children managed their own risks separate from teacher influence. The children rarely rushed into a risky situation without testing or questioning the action or environment. Oftentimes they would take sequential steps as part of completing an entire risky movement. Outdoor play provides children with adventure, challenge, and an element of danger that adds to them develop both confidence and skills in self-regulation and problem solving through positive play experience. It is evident that children engage in risk-taking behaviours and are capable of assessing their own tolerance for risk.

\section{Types of play}

Collecting (the gathering of materials from the loose parts pile), sorting, and placing the loose parts were observed as part of children's play. Generally, the collection of items occurred once a theme was identified by the children, created, and played out. For example, the materials were collected for a dramatic purpose such as weapons, buckets for making food, wood for a campfire, or decorations for their home. The placement of collected materials was usually around a focal point or an important point of reference for the purpose of creating and building areas or homes. For instance, in one situation, a group of children took turns collecting loose parts and placed them next to or around a tree stump inside their pretend home.

Dramatic and combined play (dramatic and constructive mix) were the second most common play types. Dramatic play was evident near the forest called "The Monkey Jungle." Dramatic roles were also positioned using loose parts, such as sticks becoming guns or a pipe becoming a fire hose. Combined types of play also occurred, such as when one boy constructed an obstacle course made out of a variety of loose parts that included tires, wooden boards, rope, and pipes. This construction was later (approximately 10 minutes) used as a boat and then as a surfboard. Functional play was apparent, but did not change significantly over the observation period. Common functional play behaviours were chasing, jumping, and rolling rocks down sloped areas. There was some evidence of games with rules, such as a made-up hockey game with sticks and buckets.

\section{Gender behaviour}

Observations of gender differences during this study were limited in scope. The boys and girls played together across many play episodes and used the materials in similar ways. Generally, boys engaged in more weapon, rough-and-tumble, and good versus bad themes. However, the girls also engaged in these activities and themes. Interestingly, the boys often engaged in play themes such as "house" and "family" that are usually viewed more often in the play of girls. At no time did the children verbalize to their peers that they could not play due to their 
gender. The natural outdoor setting and loose-part materials do not regulate what is and what is not possible. The natural outdoor environment and the provision of gender-neutral loose parts supported gender-inclusive and equitable play.

\section{Age differences}

Generally, all ages played together in a positive way. For example, both the young and older boys engaged in play that involved chasing the bad guys and saving the other children. They all collected materials to build houses, and all the 4- and 5-year-old children engaged in a game of tug o' war. There were some instances where younger children were excluded from play areas. For example, the older children determined who entered a play theme and how often. They would yell at the younger children upon entering their area or for stealing their items. These behaviours seemed to surface more depending on the dramatic theme that children were engaged in.

Age differences were apparent when it came to role creation and management, which were conducted by the older children. The younger children took on complementary roles when playing with older children, while the older children assumed the leader or decision-maker roles. The younger children listened and obeyed those decisions or assigning of tasks.

The neutrality of the loose parts ensured that materials were not age specific, and therefore age divisions in their use were not observed. The natural outdoor environment promoted age inclusion due to its large area, openness, and lack of play structures; the mixed ages were inclined to play together for these reasons.

\section{Implications}

The findings suggest and provide evidence that loose parts within a natural outdoor environment offer children a variety of opportunities for play, social interaction, language use, risk taking, and inclusivity of gender and age. The findings may be used to inform early childhood outdoor play policies, practice, and setting of future research agendas on the influence loose parts have on children's play in early childhood settings.

The value of this research extends beyond the immediate developmental influences that loose parts may have for children. The benefits reinforce the importance of children having access and opportunities to engage in unstructured, natural outdoor play in Canadian provinces and territories. Extending our knowledge on the importance of loose parts and outdoor play will help to solidify outdoor play regulations for early years programs. Research on the benefits of loose parts and outdoor play may help reduce the barriers of risk taking and the negative attitudes that adults may have toward loose-parts play (Staempfli, 2009) or about the value of outdoor play to development. With an increased understanding of how children use loose parts in natural environments, we become more accepting of their properties and have a willingness to ensure that they are available. For children to benefit from loose parts in their play, it is necessary for early childhood educators to advocate for unstructured play in natural landscapes. Providing professional development to early childhood educators on the importance of loose-parts play and the application of such materials is necessary (Leggett \& Newman, 2017).

Research on natural outdoor environments and loose parts is important for advancing opportunities for childdirected play spaces. This research illustrated to early childhood educators that the implementation of loose parts in an outdoor environment is easy, affordable, and advantageous for children's development. Early childhood educators can replicate this research in a variety of settings, including early years programs, family spaces, and school environments. Providing children with loose parts will expand their imaginations and positively influence their cognitive, social, emotional, and physical development. 
Future research on loose parts in natural outdoor settings may consider having early childhood educators and children report on their own experiences, as this would strengthen the accuracy and depth of the findings. Interviews with early childhood educators to understand their thoughts and feelings regarding their observations of children's play with loose parts may further expand the body of literature on the power of loose parts in outdoor play. Interviews with children could be useful in creating a loose-parts material list of items that they wish to play with. Having children tell their stories about their play with loose parts may help researchers understand what children think about while using loose parts in their play. Linking self-reports with observations would expand the research and create meaningful findings that would support early childhood educators in the implementation of loose parts in outdoor play settings.

\section{Acknowledgements}

We wish to thank the children, early childhood educators, and parents of the childcare centre that participated in this project.

\section{References}

Änggård, E. (2011). Children`s gendered and non-gendered play in natural spaces. Children, Youth, \& Environments, 21(2), 5-33. doi: $2110169830378 \mathrm{~d}$

Boldemann, C., Blennow, M., Dal, H., Mårtensson, F., Raustorp, A., Yuen, K., \& Wester, U. (2006). Impact of preschool environment upon children's physical activity and sun exposure. Preventive Medicine, 42(4), 301-308. doi: 10.1016/j.ypmed.2005.12.006

Bronfenbrenner, U. (1979). The ecology of human development: Experiments by nature and design. Cambridge, MA: Harvard University Press.

Canning, N. (2010). The influence of the outdoor environment: Den-making in three different contexts. European Early Childhood Education Research Journal, 18(4), 555-566. doi: 10.1080/1350293X.2010.525961

Chakravarthi, S. (2009). Preschool teachers' beliefs and practices of outdoor play and outdoor environments (Doctoral dissertation). Retrieved from http://citeseerx.ist.psu.edu/viewdoc/download?doi=10.1.1.453.1839\&rep=rep1\&type=pdf

Daly, L., \& Beloglovsky, M. (2015). Introducing loose parts to preschoolers. Teaching Young Children, 9(1), 18-21.

Dietze, B., \& Kashin, D. (2012). Playing and learning in early childhood education. Toronto, ON: Pearson Education.

Ernst, J. (2014). Early childhood educators' use of natural outdoor settings as learning environments: An exploratory study of beliefs, practices, and barriers. Environmental Education Research, 20(6), 735-752. doi: 10.1080/13504622.2013.833596

Gibson, J. J. (1977). The theory of affordances. In R. Shaw \& J. Bransford (Eds.), Perceiving, acting, and knowing: Toward an ecological psychology (pp. 67-82). Hillsdale, NJ: Lawrence Erlbaum.

Leggett, N., \& Newman, L. (2017). Play: "Challenging educators' beliefs about play in the indoor and outdoor environment. Australasian Journal of Early Childhood, 42(1), 24-32. doi: 10.1080/03004430.2015.1028394

Maxwell, L. E., Mitchell, M. R., \& Evans, G. W. (2008). Effects of play equipment and loose parts on preschool children's outdoor play behavior: An observational study and design intervention. Children, Youth, \& Environments, 18(2), 36-63. doi: 10.7721/ chilyoutenvi.18.2.0036

Milteer, R. M., \& Ginsburg, K. R. (2012). The importance of play in promoting healthy child development and maintaining strong parentchild bond: Focus on children in poverty. Pediatrics, 129(1), 204-213. doi: 0.1542/peds.2011-2953

Nicholson, S. (1971). How not to cheat children: The theory of loose parts. Landscape Architecture, 62, 30-35.

Perry, B. (2004). Maltreatment and the developing child: How early childhood experience shapes child and culture [Abstract]. The Inaugural 
Margaret McCain Lecture, The Centre for Children and Families in the Justice System. Retrieved from http://www.lfcc.on.ca/ mccain/perry.pdf

Rich, D. (2003). Bang, bang! Gun play and why children need it. Early Education, 1-6. Retrieved from http://www.richlearningopportunities. co.uk/index.php/publications/archive-articles-and-publications

Ridgers, N. D., Knowles, Z. R., \& Sayers, J. (2012). Encouraging play in the natural environment: A child-focused case study of forest school. Children's Geographies, 10(1), 49-65. doi: 10.1080/14733285.2011.638176

Staempfli, M. B. (2009). Reintroducing adventure into children's outdoor play environments. Environment and Behavior, 41(2), $268-280$. doi: $10.1177 / 0013916508315000$

Stephenson, A. (2002). Opening up the outdoors: Exploring the relationship between the indoor and outdoor environments of a centre. European Early Childhood Education Research Journal, 10(1), 29-38. doi: 10.1080/13502930285208821

Tremblay, M. S., Gray, C., Babcock, S., Barnes, J., Bradstreet, C. C., Carr, D., ... \& Herrington, S. (2015). Position statement on active outdoor play. International Journal of Environmental Research and Public Health, 12(6), 6475-6505. doi: 10.3390/ijerph120606475

Waller, T. (2007). "The trampoline tree and the swamp monster with 18 heads": Outdoor play in the foundation stage and foundation phase. Education 3-13, 35(4), 393-407. doi: 10.1080/03004270701602657

Zamani,Z. (2012). The comparison of cognitive play affordances within natural and manufactured preschool settings. Emergent Placemaking, May, 162-167. Retrieved from http://c.ymcdn.com/sites/edra.site-ym.com/resource/resmgr/docs/StudentPaper2ndPlace Zamani.pdf 